Article

\title{
Winning Over the Players: Investigating the Motivations to Play and Acceptance of Serious Games
}

\author{
Ruud S. Jacobs \\ Department of Communication Science, University of Twente, 7522NJ Enschede, The Netherlands; \\ E-Mail: r.s.jacobs@utwente.nl
}

Submitted: 31 May 2020 | Accepted: 24 July 2020 | Published: 6 January 2021

\begin{abstract}
Serious games are designed to educate, train, or persuade their players on specific topics and issues. While a lot of studies have sought to prove the effects of these games, the overall image and legitimization of serious games has not benefited fully from these efforts. Indicating that the issue stems from the difference between the captive audience exposed to games in effects studies and the contexts in which people come to play serious games in everyday life, the current article sketches out the research that needs to be performed before this gap can be filled. Three theoretical perspectives are offered, in turn looking at serious games as forms of (promotional) communication, personal media experiences, and technological innovations. This analysis results in insights relating to (among others), how the identity of serious games might hinder their diffusion, how expected gratifications could fail to match the intentions of these games, and what could cause someone to 'adopt' a serious game. Based on the insights gained by applying these lenses, potential factors are listed and linked to methodologies that could prove or disprove their importance. These methodologies involve quantitative and qualitative investigations to create a deeper picture of how potential players approach serious games. The article concludes with open questions to investigators and industry professionals generated from this process.
\end{abstract}

\section{Keywords}

acceptance; adoption; attitudes; games for change; media psychology; motivation; persuasive games; serious games

\section{Issue}

This article is part of the issue "Games and Communication-Quo Vadis?" edited by Marko Siitonen (University of Jyväskylä, Finland), Felix Reer (University of Muenster, Germany) and Teresa de la Hera (Erasmus University Rotterdam, The Netherlands).

(C) 2021 by the author; licensee Cogitatio (Lisbon, Portugal). This article is licensed under a Creative Commons Attribution 4.0 International License (CC BY).

\section{Introduction}

Despite their name, games have long been recognized to provide more than just playful entertainment to players. From assertions that games were used by ancient peoples to stave off hunger (McGonigal, 2011) to arguments that games subvert established ways of thinking (Flanagan, 2009), game academia abounds with demonstrating the purposes of what are-by most lay accounts-simply playthings. Nowhere is this more obvious than with the different etymological strands for games that are designed to cultivate attitudes, knowledge, competencies, and skills. The competing terms impact games, games for change, educational games, and (perhaps most of all) serious games show that indus- try and academia are attempting to legitimize the medium, or at the very least set games with these intentions apart from entertainment experiences. Considering there is as of yet no consensus on which term fits best (Breuer \& Bente, 2010), true legitimization is likely still some way off. The current article notes the progress that has been made in this regard, identifies the most important gap in serious game research, and proposes a set of methods to start filling this gap.

One of the ways in which researchers contribute to legitimization of serious games is by validating them. Validation research typically involves testing a game's effects on players against various types of control group. The qualifier 'typically' is used here because there is no standard format for validating all existing forms of 
serious gaming. This is understandable given the limitless range of attitudinal, cognitive, and behavioral effects these games are designed to exert and the equally unexplored arsenal of mechanisms serious games can be fitted with to exert these effects. There will never be a unified measurement method to explain and compare influences, nor is there a single research setting perfectly suited to exploring all mechanisms. In 2015, John Sherry lamented the lack of standardized pedagogical validation methods for educational games (here seen as a cognitively-focused subset of serious games), pointing out that results are determined per intervention and that researchers should temper their enthusiasm and demonstrate more 'vision' (Sherry, 2015, p. 129). He decried the absence of a 'Sesame Street' of educational games, referring to this seminal children's program's adherence to evidence-based pedagogical design methods. Apart from the notion that serious games had not yet reached the critical mass necessary for their diffusion when these statements were made (Uskov \& Sekar, 2015), the fragmentation that was mentioned previously might be the biggest obstacle: Progress made in validating serious games to combat cyberbullying behaviors and bystander effects (DeSmet et al., 2018) does not necessarily aid those looking to design games to educate individuals with autism (Whyte, Smyth, \& Scherf, 2015). In comparison to the range afforded by serious games as a medium, Sesame Street's remit is much more contained.

It is clear-for many reasons-that we are not yet there, five years on from Sherry's (2015) indictment of educational games research. Medium-wide evidencebased design strategies might not be feasible (or even desirable). However, the progress that has been made should not be denied. There is growing support for the notion that games affect their players in intended ways when tested in controlled settings. A review of this literature is beyond the scope of the current article, but positive and small outcomes have been established among games for learning (All, Núñez Castellar, \& Van Looy, 2016; Clark, Tanner-Smith, \& Killingsworth, 2016), skill development (e.g., Dankbaar et al., 2016; IJgosse, van Goor, \& Luursema, 2018; Wouters, van der Spek, \& van Oostendorp, 2009), and persuasion (Jacobs, 2018). With some exceptions (Soekarjo \& van Oostendorp, 2015; van 't Riet, Meeuwes, van der Voorden, \& Jansz, 2018), serious games show robust influences on those that have played them when compared to various control conditions (Boyle et al., 2016). Despite these promising results, serious games remain a niche communication tool. Something is missing before the medium can be accepted. The current article argues that this gap is less related to how games affect whoever plays them and more to who plays these games in what contexts, and why they do so.

\section{Effects versus Impact}

Speaking from anecdotal experience, serious game researchers presenting effects studies to a lay or pro- fessional audience are often posed a number of questions that evince that the public is better aware of this gap than researchers are. Questions run the gamut from 'Who plays these games (outside of the laboratory)?' and 'I do not know of any serious games myself, right?,' to the more charged 'Why is no one playing these games?' and the understandable 'Why would anyone play a game that openly tries to change them in some way?' These questions do not doubt whether the games work as intended on a captive audience; they center on the decision to play serious games at all. The distinction here is between audiences that are directed to the game specifically to participate in a study and a game's 'natural players,' which are the people that encounter or seek out serious games as part of their daily life either by personal choice (Jacobs, 2017) or through participation in educational or organizational curricula (Bourgonjon et al., 2013). In this way, the public interest in serious game research lies less with effects-a term for the direct influences a game exerts on any players-and more with effectiveness or impact, which denote influences a game exerts in the real world (de la Hera Conde-Pumpido, 2019). The gold standard of randomized controlled trials (RCTs; Boyle et al., 2016) cannot feasibly achieve information on serious game impact, as it relies inherently on abstracted (i.e., controlled) research settings. Respondents in such studies cannot choose to play or not play, as this would introduce confounds into the protocol. Any influences found in this way have high internal validity, though it says little about how the game would fare when released to the public. Evidently, other types of investigation are required in conjunction with RCTs to validate impact.

Returning to a previous point, serious games have something to prove that Sesame Street does not: The penetration of Sesame Street was apparent to most parents with access to a television set in countries across the world for decades, facilitating the program's pedagogical legitimization through research. Serious games, on the other hand, are invariably not nearly as popular, do not spring from a single, reputable source, and in some cases attempt to hide their intended effect behind a veneer of trivial fun (Spagnolli, Chittaro, \& Gamberini, 2016). These factors of popularity (or virality), source and context, and communicated intent potentially affect their visibility as well as their player base. In truth, the vast majority of people nowadays have played serious games, from math games during school hours to typing games to improve keyboard proficiency and advergames on the interminable Flash portals of yesteryear. The cross-media public service announcement campaign 'Dumb Ways to Die' has caused hundreds of millions of players to try to prevent its cutesy characters from perishing in avoidable accidents, presumably picking up on the games' messaging on railway safety while chasing high scores.

With a few exceptions (e.g., Bourgonjon, Valcke, Soetaert, \& Schellens, 2010), we know very little about why people played these games, the experiences they 
had that caused them to stop or continue playing, or what drives them to remember their time with a game and maybe even share the game with friends (Cohen, 2014). Knowing more about this side of player experience is vital to help determine which elements of games are important attractors. In turn, this information could be used to improve game design strategies to make them more impactful. The following section discusses several theoretical approaches to player choice and experience, with Section 4 recommending methods that could provide empirical knowledge on these topics.

\section{Theoretical Perspectives on Serious Game Player Agency and Motivation}

This section discusses player choice in serious games from three different theoretical perspectives. The first approaches serious games as a form of communication that is also brought to players through persuasive communication. Second, serious games are mediapsychological experiences that are sought out to gratify certain needs. Finally, serious games can be seen as innovative technologies that diffuse through society in recognizable patterns. Each perspective yields separate but overlapping considerations that can inform future research.

\subsection{Serious Games as Promotional Communication}

By now, the notion that games are a form of communication is not seen as controversial, though few treat them as such. All games can (and many do) carry messages from developer to player. The reliability with which players will pick up on these messages as they were intended is a matter of some debate (Sicart, 2011), as some theorists argue that player agency and intention could skew interpretations of the already very playerdriven experience of playing a (serious) game. While differential decoding seems intuitively plausible, the studies discussed so far demonstrate this could only result in unsystematic error in persuasive effects. Unfortunately, few studies have applied theories of communication to this rich setting, meaning monodisciplinary effect studies tend to treat games as black boxes (e.g., D. Ruggiero, 2015). Studies that do not, such as Peng, Lee, and Heeter's (2010) foray into disentangling the influences of interactivity and audiovisual content of Darfur is Dying, do not draw from communication theories to support their manipulations.

Although theoretical bridges are being built from social sciences (e.g., Malliet \& Martens, 2010) and from design sciences and humanities (e.g., Christiansen, 2014), the two have not yet met in the middle with conclusively validated psychological mechanisms of serious games. Theoretical arguments made on the side of players so far involve cognitive load (of playing and attending to a message), enjoyment (discussed in Section 3.2), and mental models (to build an understanding of game systems and how they translate to the real world). These arguments all fit well with dual-system theories of persuasion such as the heuristic-systematic model (HSM; Chen \& Chaiken, 1999) or the elaboration likelihood model (ELM; Petty \& Wegener, 1999). Put simply, lasting persuasive impact can be attained by enabling and encouraging personal reflection on strong arguments. On the other hand, short-term, shallower persuasive influences can be established even from weak arguments, as long as they are delivered in a credible way and discourage reflection. The connotations this holds for serious games have yet to be explored fully, though Vyvey, Núñez Castellar, and Van Looy (2018) show many questions still have to be answered.

Completely unexplored, however, are the implications dual-system theories of processing (or indeed any other communication theories) have for attracting players. Important factors of the ELM are individual characteristics such as personal relevance (Malliet \& Martens, 2010) and enduring traits like the need for cognition (Cacioppo \& Petty, 1982), which both influence the kind of audience a game can attract. Personal relevance predicts that a game will be played with full attention mostly by the part of its audience that sees the subject of the game as personally relevant to them, while differences in need for cognition would mean that games that seem to be cognitively demanding might deter even more segments of the target audience.

Then there is also the way in which the game itself is communicated and promoted. The distinction between games that are played voluntarily and those that are not is made in Section 3.3, but assuming a game is freely available, the choice to play is very likely contingent on how the game is presented to potential players. Should a serious game advertise itself as such and wear its intended influence on its sleeve, or should it obfuscate its intentions with, as in the example of Figure 1, cutesy visuals and enjoyment-focused attract messages? In a study by Vagg et al. (2018), patients with cystic fibrosis using an MHealth application "commented that they liked that the app icon and game style as it does not appear to be for their [cystic fibrosis] and as such each participant felt comfortable playing in front of friends or in public" (p. 104). This suggests that answers to the question above might be specific to certain audiences, topics, and play settings.

How to advertise serious games is as much an ethical issue as it is an empirical question about their success and impact. When extrapolated, the persuasion knowledge model (Friestad \& Wright, 1994) would predict that potential players would be less likely to play a serious game that is clear about its intent as they would want to shield themselves from potential influences. On the other hand, they could also appreciate the candor of this presentation if personal relevance for the message is high and the game's position on the topic is in line with their own. In a rare study on the importance of source motivation on enjoyment of an advergame (a serious game made for marketing purposes), Ham, Yoon, and 


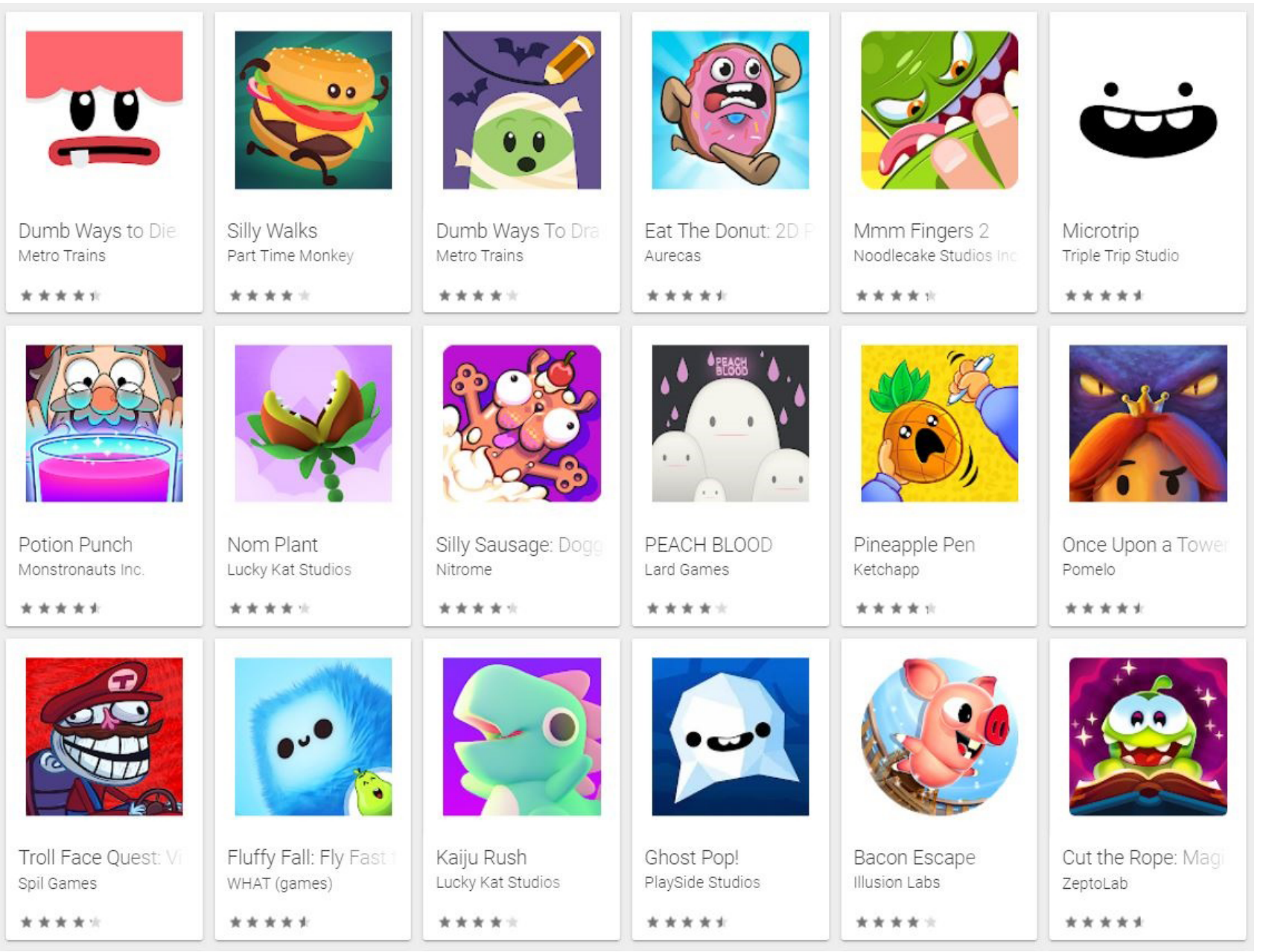

Figure 1. A screenshot of the Google Play Store: Should uninitiated users be able to tell serious games apart from entertainment games? Source: Google Play Store (n.d.), screenshot by author.

Nelson (2016) showed that playing a food advergame from an impartial source (versus a commercial source) resulted in improved attitudes towards food brands, but not in more enjoyment of the game itself. In other effect studies, message obtrusiveness and persuasion knowledge have been found to relate to serious game influences and experiences in various ways (Jacobs, 2017) that require further research to delineate, which means care must be taken to do this variable justice in investigations into the choice to play serious games.

\subsection{Serious Games as Media Experiences}

Even when setting aside persuasion knowledge, serious games tend to result in very different gameplay experiences from their commercial-off-the-shelf (COTS) entertainment counterparts. Current mediapsychological theories of play motivations and experiences do not necessarily translate from COTS games to serious games. One area that extant research shows to be very salient in this regard is the importance of enjoyment, and more specifically the granularity with which this concept is operationalized. While broader mediapsycholog- ical research has long since acknowledged that 'fun' is wholly inadequate as a construct for capturing positively rewarding experiences with media (Oliver \& Bartsch, 2011), this kind of thinking has only recently begun to be applied to COTS games (Daneels, Vandebosch, \& Walrave, 2020), and serious game research has not yet caught up (Crutzen, van 't Riet, \& Short, 2015).

By virtue of discussing a 'serious' topic, serious games are more likely to elicit eudaimonic appreciationmeta-emotional sensations that often result in feelings of personal growth - than the more fun-focused hedonic enjoyment. To be sure, any game can offer both types of gratification, but they also do not necessarily need to trade on fun to keep players engaged, contrary to the truism among serious game researchers (e.g., Spagnolli et al., 2016). Whether or not this same flexibility of gratifications offered extends to pre-play attitudes towards serious games and, most importantly, the choice to start playing one, has not yet been investigated. Do potential players seek out freely available serious games to scratch a eudaimonic itch, as they for example look to learn more about the warning signs of dating violence (Crecente, 2014), or do they need to be lured in with 
promises of the same kind of playful fun they expect from most COTS games? The latter outcome would lend credence to the oft-maligned cartooning of serious games as akin to 'chocolate-covered broccoli' (for example, see Hopkins \& Roberts, 2015), with the nutritious center representing the positive influence of a game that is separate from and incongruent with the external coating of trivial, light-hearted entertainment. At the same time, this would contradict stories of the relative success and popularity of titles that seem to eschew fun, like Darfur is Dying (Cohen, 2014) and the teen dating violence games referred to previously. A longer discussion of the entanglement of fun with the objectives of serious play is necessary, since even the broader concept of play itself is often linked to learning and training (e.g., Samuelsson \& Carlsson, 2008). For reasons of brevity, let us conclude that 'play' should not be seen by serious game researchers as a vehicle for fun alone.

Of course, hedonic and eudaimonic gratifications are just two of a number of possible reasons players might expose themselves to this kind of experience. Direct applications of the uses and gratifications approach to media choice (Katz, Blumler, \& Gurevitch, 1973; T. E. Ruggiero, 2000) among serious games are lacking. In their early literature review, Connolly, Boyle, MacArthur, Hainey, and Boyle (2012) already noted this gap and pointed to its application to COTS games instead. Unfortunately, the list of reasons generated by Lucas and Sherry (2004), comprising competition, challenge, social interaction, diversion, fantasy, and arousal, does not translate intuitively to serious gaming. The three high-level needs of autonomy, relatedness, and competence posited as part of self-determination theory (Ryan, Rigby, \& Przybylski, 2006) might fare better when operationalized in a fitting way. Still, Connolly et al. (2012) report conflicting results on motivations to play math and history games that highlight the knowledge gap on which factors from entertainment games can be taken into account when considering serious game uses and gratifications.

Coming in from the opposite end of the entertainment spectrum, a study on health applications concluded that whether or not existing users intended to continue using apps depended on how they perceived the apps' ability to register their data, enable sharing and discussion of these data with peers, present information credibly and comprehensibly, and even whether or not the app was seen as fashionable (Lee \& Cho, 2017). At the same time, informational accuracy and entertainment value were unrelated to intention to continue use. If serious games are seen as falling somewhere between recreational and utilitarian, perceived gratifications should be drawn from both fields of research. Research into this topic should of course enable and encourage responses beyond these two poorly fitting paradigms and be open to altogether new constructions of serious game uses.

One last consideration comes forward when serious games are seen as media products. Although it has been a matter of some contention whether popular entertainment media reception is influenced by or simply predicted by their coverage in critical outlets (Eliashberg \& Shugan, 1997), recent investigations found that -at least for games-critics indeed influence sales of COTS games (Sherrick \& Schmierbach, 2016). Unfortunately, while industry-facing outlets such as Edge Magazine occasionally cover some serious games, public coverage of these games is dwarfed by that of their COTS counterparts. Comparing a serious game such as Attentat 1942 (Mago, 2019) with the predominantly COTS-oriented This War of Mine (also discussed by de Smale, Kors, \& Sandovar, 2019) on Metacritic shows that the latter was discussed by around five times as many professional critics (63 versus 13 , at the time of writing) and over a hundred times as many consumer reviewers ( 895 versus 8 ) than the former, even though both are sold on the popular PC gaming platform Steam. Serious games are not being measured by the same media product standards as entertainment games. Unfortunately, serious game criticism is equally underrepresented in the literature, so there is as yet no empirical data to support this contention.

\subsection{Serious Games as Innovative Technologies}

To provide more depth to the utilitarian side, we can see serious games as technological innovations that aim to diffuse through society and saturate the target audience. From this viewpoint, innovation diffusion theory (Rogers, 2003), and the second iteration of the unified theory of acceptance and use of technology (Venkatesh, Thong, \& $X u, 2012)$ become salient. These theories emphasize the decision to adopt, use (or play) an innovation, conceptualizing it as an agentic choice that is either made once or that is revisited a few times. This realization splits the audiences of serious games into two. On the one hand there are the types of games that have been discussed the most up until this point; games that are developed to be placed online (or distributed in other ways) and are most often playable free of charge once the player seeks them out or gets them pointed out by peers. These serious games are often persuasive games with pro-social (Jacobs, Jansz, \& de la Hera Conde-Pumpido, 2017) or advertising purposes. I refer to players of these games as 'natural players' as a short-hand for describing an uncoerced, organic adoption process. Serious games aiming for natural players most often have to promote themselves or be part of a cross-media campaign to stand a chance of 'going viral' (Cohen, 2014). Natural players are free to allocate more or less time to a serious game, or choose playing a serious game over other activities. This decision process is much like the adoption process of innovative technologies.

Contrast games for natural players with the rest of serious games, and the decision point and agency change. Educational and skill-training games such as Underground (Goris, Jalink, \& ten Cate Hoedemaker, 2014) are not available to individual players at little to 
no cost. They are embedded in (formal) educational programs or skill training courses. While most of these settings do not involve coercing play and often present the opportunity to opt out, the players themselves do not choose the game separately from the program, and their progress in this program can sometimes be contingent on their participation. Just like with RCT effect studies, this player group is referred to as a 'captive audience.' While serious games are presumably made for captive audiences, they are not marketed to them. Instead, they aim at the institutions or organizations that would make these games available in their programs. In the interest of the current article's focus, this discussion is limited to player choices and experiences even if the decision to use a game does not lie with the players but with their educators (Bourgonjon et al., 2013), caretakers (Bourgonjon, Valcke, Soetaert, De Wever, \& Schellens, 2011), or even their managers (Riedel, Feng, \& Azadegan, 2013). Readers should note that the distinction between natural and captive players depends not on any qualities of the game itself, but on how it is distributed, used, and/or applied.

I separate games for natural and captive audiences because different facets of acceptance and adoption are likely to contribute to the success of either type. As an adoption theory, innovation diffusion theory (IDT; Rogers, 2003) can aid in mapping the spread of a game among natural players. The individual's path to becoming a serious game player involves knowledge, persuasion, and decision stages. In the knowledge stage, would-be players first have to learn about the existence of a game and its topic. Serious game visibility is often quite low, as they jostle for attention with COTS games that often have much larger marketing budgets. Assuming that a potential player has learned about a game's existence, IDT proposes that they then need to be persuaded about the value of playing it. A game has relative advantage when it is perceived to better fulfill players' goals than competing works or activities. It should also appear compatible with the player's lifestyle. While this sounds vague, perceptions of what a game is can influence motivations to play and push away potentially valid sections of the target audience. This is related to complexity, as a game also needs to appear easy to start playing. This would suggest quick-fire, simply animated games such as Dumb Ways to Die draw in more players than complex 3D experiences with tutorials explaining its many systems like Fate of the World. Trialability is likely not an important factor for freely available games. Finally, games need to be observable, for instance by encouraging sharing on social media, or pushing players to discuss the game and topic with others. It is intuitively likely that these factors influence how many natural players flock to a serious game, but there does not seem to be any empirical work supporting this claim.

Returning to the ways serious games are labeled, promoted, and presented, the adoption perspective highlights a common-sense problem: Why would potential players choose a game that is labeled as 'serious' over normal games? Given the variety of monikers and wildly varying player counts across serious games, the current serious gaming landscape seems ready for investigations into the factors that cause natural players to accept or reject serious games. The difficulty in this investigation would be epistemological: How do we know a game to be serious (enough), and what kind of experiences are included here? Attentat 1942 and its earnest and melancholic handling of historic subject matter and references to in-classroom use easily make it a serious game-arguably more so than the more popular, fictionalized This War of Mine. It is unknown to what degree the difference in popularity and renown comes down to This War of Mine's abstraction of the setting.

Looking at captive audiences, an exploratory investigation demonstrated that the decision to use serious games tends to come from supervisors and managers (Riedel et al., 2013). The loss of player agency is reflected in the success or failure of the game's implementation, as it depends on corporate culture rather than individual attitudes. As indicated previously, the current article is limited to players' experiences for the sake of focus. The second unified theory of acceptance and use of technology (UTAUT2; Venkatesh et al., 2012) is better suited to exploring the acceptance (rather than adoption) of serious games by the captive players themselves. This model includes seven factors that would influence play behavior intention directly: performance and effort expectancy, social influences, facilitating conditions, hedonic motivations, price value, and habit. Although voluntariness was not included in this iteration of the model, it is applicable to serious games for captive audience, who have some degrees of freedom in deciding to play or not. For the player, effort expectancy, social influences, and hedonic motivation seem the most important factors. Players need to feel they are able to play without expending too much effort, see playing the game as a social activity that might fuel a discussion (wherever possible and applicable), and feel like the game gives them a positive experience-though, again, that should be operationalized more deeply than mere fun or hedonic enjoyment. Performance expectan$c y$, facilitating conditions, and price value could be important factors for those responsible for embedding the game into educational practice. Finally, experience with games and demographic characteristics moderate the influences of these factors on actual play behavior, even though generational shifts serve to make basic gaming capital more and more common across societal strata (Kneer, Jacobs, \& Ferguson, 2018).

\section{Methodological Considerations for Comprehensive Impact Validation}

The previous section is intended to generate more questions than can be discussed here. Many of these questions are organizational or sociological in nature, probing 
the corporate and institutional cultures that can help or hinder managers in choosing for skill training methods (Riedel et al., 2013), for instance. More economical questions surround the financial feasibility of serious games as a function of their scalable nature and (highly topical) affordances for implementing in work-from-home settings. While these questions are highly important for the broader issues of legitimization and validation, the current article prioritizes individual agency. Within that scope, combining insights from the three theoretical angles discussed until now yields a number of important issues that need to be explored to approach an individualistic view on impact validation of serious games. A host of intra-individual perceptions and attitudes of would-be players flow from the previous discussion:

- Perceived differences between serious games and COTS games.

- A-priori perceptions of the experience of playing serious games (including persuasion knowledge, enjoyment, and appreciation).

- What serious games are being compared to (COTS games, traditional instructional methods, other persuasive media).

- Descriptive and injunctive norms around playing serious games in multiple audience segments.

- The salience of self-efficacy (the perceived ability to play serious games).

- Cognitions about time and effort investment required to play serious games.

- Differences between novelty attractors and persistent engagement.

- The importance of perceptions of voluntariness and free choice.

Note that this representation of the issues that still require attention in serious gaming is limited to intraindividual factors. I focus on these issues with the aim of providing handholds for further research towards legitimization and validation of the medium. Of course, they do afford investigations from different perspectives and taking place in diverse contexts. For example, when studying natural players, the focus should lie with attractors that enhance the adoption of serious games and potential barriers such as self-efficacy and displacement of other activities. Word of mouth should also be central here. Among captive audiences, distinguishing formal education and (adult) skills training might be fruitful. In the former, the focus should be on accepting games as part of the curriculum (Bourgonjon et al., 2010), the voluntariness of play, and expectations of what serious play entails. The latter setting affords investigations into acceptance of the use of games for these purposes, more nuanced distinctions in voluntariness, and the importance of social factors.

Rather than suggest a single gold standard research paradigm such as the RCT for in-lab validation, I advise the concurrent application of quantitative and qualita- tive methods. Starting with quantitative research, there is a need for (longitudinal) surveys of target groups, potential players, and actual players with data collection waves that are tied to a high-profile serious game launch. These surveys can track how multiple sets of attitudes and beliefs change over time and predict key outcomes such as finishing a game, persistent play, or behavior change. To prevent loss of power because of low visibility of the game and weak penetration, surveys could manipulate or control for the knowledge stage in IDT by informing the sample of the game's launch.

At the same time, only qualitative investigations could hope to show blind spots in current thinking about experiences with serious games. What is needed is a firmer understanding of the personal and social construction of the identity of serious games and the acceptability of games that are known (or not known?) to teach and persuade. Asking a captive audience to keep play diaries would demonstrate the path from initial appraisal through continued use and how observable the game is to the player's social environment. Potential players could be interviewed when a target audience is very specific, such as with Snow World, a pain-suppressing experience for burn victims (as discussed by de la Hera Conde-Pumpido, 2017). These interviews should probe expectations prior to play, and possibly be revisited after play. Taking a cue from human-centered design processes, use-based observational methods can help pinpoint what potential natural players look at before and during play. Lastly, captive audiences in (formal) education settings afford observation and focus group studies to learn more about how games are currently embedded in curricula and how class-based debriefing discussions (Crookall, 2014) contribute to perceptions of social norms and constructions of the worth of serious games.

In practice, researchers interested in investigating the real-world impact of serious games need to be opportunistic. Truly interdisciplinary research endeavors are rare and misaligned production cycles can easily cause these efforts to yield suboptimal outcomes. Researchers should prepare collaborations with multiple industry partners before production has begun. They need to be able to design a study around a game that is soon to launch, and roll out this study while collaborating with industry partners. One important source of data that is currently all too often out of reach of player-focused researchers are logged play data. As demonstrated by Smith, Hickmott, Southgate, Bille, and Stephens (2016), logging play behaviors can provide an additional layer of objective information, showing how long players spend on parts of the game, or the order in which they progress through it. Though these data might typically be seen as control variables in quantitative studies, they can also serve as outcome measures when investigating player persistence. More importantly, they can also provide input for qualitative research, helping players to discuss issues they had with a game (i.e., a memory aid) or to support subjective play diaries with more precise behavioral 
data. Situations in which collaborations with industry are intensified could allow for aggregated data loggingmeaning play data from regular players are anonymously and unobtrusively collected. Despite the enormous promise of this data type in charting games' impacts, studies using these data to discuss player behavior in games are scarce in COTS games (Holl, 2019) and all but absent in serious game research.

Only by working with real-life cases can serious game research attain the external validity that is lacking from studies that involve proprietary games (which are often simply prototypes not meant for natural players). To give an example, the previously mentioned Attentat 1942 was developed quite recently by a team of academics and game developers in the Czech Republic (Mago, 2019). As this game was launched on Steam it sought natural players, though its website (http://attentat1942.com) also invites visitors to use the game in an educational setting. If social scientists had been attached to this game's development, they might have tracked the game's spread on Steam and social media. Surveys could have been timed to capture audience reactions at release, measuring word-of-mouth and expectations on the game. A post-hoc analysis of the reviews currently listed for this game could help shed light on the game's reception and the way in which the game's serious intent landed with professional critics and consumer reviewers. Play diaries would help demonstrate how the game's historical elements (Mago, 2019) were experienced by players. Summarizing, the methods discussed above could have, when applied, yielded a lot of information on how Attentat 1942 reached and touched players. Naturally, this also means that organizations developing serious games should also look to collaborate with researchers to drive validation efforts forward. Since legitimacy of the medium can help developers and creatives attract funding for their games, such a development would be in every party's interest.

\section{Conclusion}

In the current article, I attempted to show how efforts to validate serious game have hit a snag. Although there is still plenty of ground to cover before effects studies on captive audiences no longer provide new information, the focus on research participants playing games because they were asked to means that we know next to nothing about how a game will be experienced by people in the real world. By discussing serious games alternatively as promotional communication, media experiences, and innovative technologies, multiple uncharted factors became apparent. As these are almost all centered around perceptions of would-be players prior to and during their time with a serious game, several methods are proposed that (when executed) can shed the necessary light on this issue.

By design, this article generates more questions than it could hope to answer. Two of the most pertinent questions for researchers are: To what degree should or can we borrow from knowledge of entertainment games and purely utilitarian applications to explain how people experience serious games? Do we need to work towards one unified theory of serious game acceptance and adoption, or should there be distinct explanations for different types of game (advergames, skill improvement games, etc.), separate contexts and player groups, or even for the play decision point as opposed to serious gameplay persistence? Finding answers for these questions involves comprehensive investigations into the 'player's journey,' most likely starting with the stages leading to adoption and ending with persistence and any resulting knowledge, behavior, or attitude change.

On a more practical level, the article also leads to more specific questions to people developing or commissioning the development of serious games: Do you take your players' time and interests seriously? Who are you competing with, entertainment games or other forms of instruction? What are you doing to draw in players besides offering 'fun'? What are you doing to encourage word of mouth once players are done with your game? As indicated before, none of these questions can be answered with just one (type of) investigation. We need collaborative efforts-including game developers and researchers - that reflexively adapt to specific circumstances but that can still generate insights beyond an individual case. The shift from studying effects to effectiveness requires impartial, interdisciplinary investigations. The range of methods discussed here comprise the next steps towards the goal of validating serious games.

\section{Acknowledgments}

The arguments in this article are partially the result of discussions that were held during the GAMECO2019 Symposium that was hosted in November of 2019 by the Erasmus Research Centre for Media, Communication and Culture in Rotterdam, the Netherlands. The attendees and organizers of this event, along with the anonymous reviewers of this special issue, were very helpful in refining this article.

\section{Conflict of Interests}

The author declares no conflict of interests.

\section{References}

All, A., Núñez Castellar, E. P., \& Van Looy, J. (2016). Assessing the effectiveness of digital game-based learning: Best practices. Computers \& Education, 92/93, 90-103. https://doi.org/10.1016/j.compedu. 2015.10.007

Bourgonjon, J., De Grove, F., De Smet, C., Van Looy, J., Soetaert, R., \& Valcke, M. (2013). Acceptance of game-based learning by secondary school teachers. 
Computers \& Education, 67, 21-35. https://doi.org/ 10.1016/j.compedu.2013.02.010

Bourgonjon, J., Valcke, M., Soetaert, R., De Wever, B., \& Schellens, T. (2011). Parental acceptance of digital game-based learning. Computers \& Education, 57(1), 1434-1444. https://doi.org/10.1016/ j.compedu.2010.12.012

Bourgonjon, J., Valcke, M., Soetaert, R., \& Schellens, T. (2010). Students' perceptions about the use of video games in the classroom. Computers \& Education, 54(4), 1145-1156. https://doi.org/10.1016/ j.compedu.2009.10.022

Boyle, E. A., Hainey, T., Connolly, T. M., Gray, G., Earp, J., Ott, M., . . Pereira, J. (2016). An update to the systematic literature review of empirical evidence of the impacts and outcomes of computer games and serious games. Computers \& Education, 94, 178-192. https://doi.org/10.1016/j.compedu.2015.11.003

Breuer, J., \& Bente, G. (2010). Why so serious? On the relation of serious games and learning. Journal for Computer Game Culture, 4(1), 7-24. Retrieved from https://hal.archives-ouvertes.fr/hal-00692052

Cacioppo, J. T., \& Petty, R. E. (1982). The need for cognition. Journal of Personality and Social Psychology, 42(1), 116-131.

Chen, S., \& Chaiken, S. (1999). The heuristic-systematic model in its broader context. In S. Chaiken \& Y. Trope (Eds.), Dual-process theories in social psychology (pp. 73-96). New York, NY: Guilford Press.

Christiansen, P. (2014). Presence and heuristic cues: Cognitive approaches to persuasion in games. In R. Altizer, J. Zagal, A. Waern, \& S. Björk (Eds.), DiGRA '14: Proceedings of the 2014 DiGRA International Conference. Tampere: Digital Games Research Association.

Clark, D. B., Tanner-Smith, E. E., \& Killingsworth, S. S. (2016). Digital games, design, and learning. Review of Educational Research, 86(1), 79-122. https://doi. org/10.3102/0034654315582065

Cohen, E. L. (2014). What makes good games go viral? The role of technology use, efficacy, emotion and enjoyment in players' decision to share a prosocial digital game. Computers in Human Behavior, 33, 321-329. https://doi.org/10.1016/j.chb.2013.07. 013

Connolly, T. M., Boyle, E., MacArthur, E., Hainey, T., \& Boyle, J. M. (2012). A systematic literature review of empirical evidence on computer games and serious games. Computers \& Education, 59(2), 661-686. https://doi.org/10.1016/j.compedu.2012.03.004

Crecente, D. (2014). Gaming against violence: A grassroots approach to teen dating violence. Games for Health Journal, 3(4), 198-201. https://doi.org/ 10.1089/g4h.2014.0010

Crookall, D. (2014). Engaging (in) gameplay and (in) debriefing. Simulation \& Gaming, 45(4/5), 416-427. https://doi.org/10.1177/1046878114559879

Crutzen, R., van 't Riet, J., \& Short, C. E. (2015). Enjoyment: A conceptual exploration and overview of experimental evidence in the context of games for health. Games for Health Journal, 5(1), 15-20. https://doi.org/10.1089/g4h.2015.0059

Daneels, R., Vandebosch, H., \& Walrave, M. (2020). "Just for fun?": An exploration of digital games' potential for eudaimonic media experiences among Flemish adolescents. Journal of Children and Media, 14(3), 285-301. https://doi.org/10.1080/17482798. 2020.1727934

Dankbaar, M. E. W., Alsma, J., Jansen, E. E. H., van Merrienboer, J. J. G., van Saase, J. L. C. M., \& Schuit, S. C. E. (2016). An experimental study on the effects of a simulation game on students' clinical cognitive skills and motivation. Advances in Health Sciences Education, 21(3), 505-521. https://doi.org/10.1007/ s10459-015-9641-x

de la Hera Conde-Pumpido, T. (2017). Persuasive gaming: Identifying the different types of persuasion through games. International Journal of Serious Games, 4(1), 31-39. https://doi.org/10.17083/ijsg.v4i1.140

de la Hera Conde-Pumpido, T. (2019). Advergames' effectiveness. In T. de la Hera Conde-Pumpido (Ed.), Digital gaming and the advertising landscape (pp. 67-76). Amsterdam: Amsterdam University Press. https:// doi.org/10.2307/j.ctvnp0j4g.8

de Smale, S., Kors, M. J. L., \& Sandovar, A. M. (2019). The case of This War of Mine: A production studies perspective on moral game design. Games and Culture, 14(4), 387-409. https://doi.org/10.1177/ 1555412017725996

DeSmet, A., Bastiaensens, S., Van Cleemput, K., Poels, K., Vandebosch, H., Deboutte, G., . . . De Bourdeaudhuij, I. (2018). The efficacy of the Friendly Attac serious digital game to promote prosocial bystander behavior in cyberbullying among young adolescents: A cluster-randomized controlled trial. Computers in Human Behavior, 78, 336-347. https://doi.org/ 10.1016/j.chb.2017.10.011

Eliashberg, J., \& Shugan, S. M. (1997). Film critics: Influencers or predictors? Journal of Marketing, 61, 68-78.

Flanagan, M. (2009). Critical play: Radical game design. Cambridge, MA: MIT Press.

Friestad, M., \& Wright, P. (1994). The persuasion knowledge model: How people cope with persuasion attempts. Journal of Consumer Research, 21(1), 1-31. https://doi.org/10.1086/209380

Google Play Store. (n.d.). Android apps on Google Play. Retrieved from https://play.google.com/store/ search?q=dumb\%20ways\%20to\%20die

Goris, J., Jalink, M. B., \& ten Cate Hoedemaker, H. O. (2014). Training basic laparoscopic skills using a custom-made video game. Perspectives on Medical Education, 3(4), 314-318. https://doi.org/10.1007/ s40037-013-0106-8

Ham, C.-D., Yoon, G., \& Nelson, M. R. (2016). The interplay of persuasion inference and flow experience in an entertaining food advergame. Journal of Con- 
sumer Behaviour, 15(3), 239-250. https://doi.org/ 10.1002/cb.1564

Holl, E. (2019). Rise of the machines-Moral decisions in Detroit: Become Human. Paper presented at 69th Annual International Communication Association Conference, Whashington, DC, USA. Retrieved from http://hdl.handle.net/10993/39629\%0A

Hopkins, I., \& Roberts, D. (2015). 'Chocolate-covered broccoli'? Games and the teaching of literature. Changing English, 22(2), 222-236. https://doi.org/ 10.1080/1358684X.2015.1022508

IJgosse, W. M., van Goor, H., \& Luursema, J.-M. (2018). Saving robots improves laparoscopic performance: Transfer of skills from a serious game to a virtual reality simulator. Surgical Endoscopy, 32(7), 3192-3199. https://doi.org/10.1007/s00464-018-6036-0

Jacobs, R. S. (2017). Playing to win over: Validating persuasive games. Rotterdam: Erasmus Research Center for Media Communication and Culture. Retrieved from http://hdl.handle.net/1765/102769

Jacobs, R. S. (2018). Play to win over: Effects of persuasive games. Psychology of Popular Media Culture, 7(3), 231-240. https://doi.org/10.1037/ ppm0000124

Jacobs, R. S., Jansz, J., \& de la Hera Conde-Pumpido, T. (2017). The key features of persuasive games: A model and case analysis. In R. Kowert \& T. Quandt (Eds.), New Perspectives on the Social Aspects of Digital Gaming: Multiplayer 2 (pp. 153-171). Oxford: Routledge.

Katz, E., Blumler, J. G., \& Gurevitch, M. (1973). Uses and gratifications research. The Public Opinion Quarterly, 37(4), 509-523. Retrieved from http://www.jstor. org/stable/2747854

Kneer, J., Jacobs, R. S., \& Ferguson, C. J. (2018). You could have just asked: The perception of motivations to play violent video games. Studies in Media and Communication, 6(2), 1-11. https://doi.org/ 10.11114/smc.v6i2.3389

Lee, H. E., \& Cho, J. (2017). What motivates users to continue using diet and fitness apps? Application of the uses and gratifications approach. Health Communication, 32(12), 1445-1453. https://doi.org/10.1080/ 10410236.2016.1167998

Lucas, K., \& Sherry, J. L. (2004). Sex differences in video game play: A communication-based explanation. Communication Research, 31(5), 499-523. https://doi.org/10.1177/0093650204267930

Mago, Z. (2019). Attentat 1942. Apparatus: Film, Media, and Digital Cultures in Central and Eastern Europe, 9. Retrieved from http://www.apparatusjournal.net/ index.php/apparatus/article/view/181/444

Malliet, S., \& Martens, H. (2010). Persuasive play: Extending the elaboration likelihood model to a game based learning context. In R. Van Eck (Ed.), Interdisciplinary models and tools for serious games: Emerging concepts and future directions (pp. 206-225). Hershey, PA: IGI Global.
McGonigal, J. (2011). Reality is broken: Why games make us better and how they can change the world. London: Penguin.

Oliver, M. B., \& Bartsch, A. (2011). Appreciation of entertainment. Journal of Media Psychology, 23(1), 29-33. https://doi.org/10.1027/1864-1105/a000029

Peng, W., Lee, M., \& Heeter, C. (2010). The effects of a serious game on role-taking and willingness to help. Journal of Communication, 60(4), 723-742. https:// doi.org/10.1111/j.1460-2466.2010.01511.x

Petty, R. E., \& Wegener, D. T. (1999). The elaboration likelihood model: Current status and controversies. In S. Chaiken \& Y. Trope (Eds.), Dual-process theories in social psychology (pp. 37-72). New York, NY: Guildford Press.

Riedel, J. C. K. H., Feng, Y., \& Azadegan, A. (2013). Serious games adoption in organizations: An exploratory analysis. In D. Hernández-Leo, T. Ley, R. Klamma, \& A. Harrer (Eds.), Scaling up learning for sustained impact (pp. 508-513). Berlin: Springer Berlin Heidelberg.

Rogers. (2003). Diffusion of innovations (5th ed.). New York, NY: Free Press.

Ruggiero, D. (2015). The effect of playing a persuasive game on attitude and affective learning. Computers in Human Behavior, 45, 213-221. https://doi.org/ 10.1016/j.chb.2014.11.062

Ruggiero, T. E. (2000). Uses and gratifications theory in the 21st century. Mass Communication and Society, 3(1), 3-37. https://doi.org/10.1207/ S15327825MCS0301_02

Ryan, R. M., Rigby, C. S. S., \& Przybylski, A. K. (2006). The motivational pull of video games: A self-determination theory approach. Motivation and Emotion, 30(4), 347-363. https://doi.org/10.1007/ s11031-006-9051-8

Samuelsson, I. P., \& Carlsson, M. A. (2008). The playing learning child: Towards a pedagogy of early childhood. Scandinavian Journal of Educational Research, 52(6), 623-641. https://doi.org/10.1080/ 00313830802497265

Sherrick, B., \& Schmierbach, M. (2016). The effects of evaluative reviews on market success in the video game industry. The Computer Games Journal, 5(3/4), 185-194. https://doi.org/10.1007/s40869016-0027-y

Sherry, J. L. (2015). Debating how to learn from video games. In R. Kowert \& T. Quandt (Eds.), The Video game debate (pp. 116-130). New York, NY: Routledge.

Sicart, M. (2011). Game studies: Against procedurality. The International Journal of Computer Game Research, 11(3). Retrieved from http://gamestudies. org/1103/articles/sicart_ap

Smith, S. P., Hickmott, D., Southgate, E., Bille, R., \& Stephens, L. (2016). Exploring play-learners' analytics in a serious game for literacy improvement. In T. Marsh, M. Ma, M. F. Oliveira, J. Baalsrud 
Hauge, \& S. Göbel (Eds.), Serious games: JCSG 2016Lecture notes in computer science (pp. 13-24). Cham: Springer.

Soekarjo, M., \& van Oostendorp, H. (2015). Measuring effectiveness of persuasive games using an informative control condition. International Journal of Serious Games, 2(2), 37-56. https://doi.org/10.17083/ ijsg.v2i2.74

Spagnolli, A., Chittaro, L., \& Gamberini, L. (2016). Interactive persuasive systems: A perspective on theory and evaluation. International Journal of HumanComputer Interaction, 32(3), 177-189. https://doi. org/10.1080/10447318.2016.1142798

Uskov, A., \& Sekar, B. (2015). Smart gamification and smart serious games. In D. Sharma, M. Favorskaya, L. Jain, \& R. Howlett (Eds.), Fusion of smart, multimedia and computer gaming technologies (pp. 7-36). https://doi.org/10.1007/978-3-319-14645-4_2

Vagg, T., Tan, Y. Y., Shortt, C., Hickey, C., Plant, B. J., \& Tabirca, S. (2018). MHealth and serious game analytics for cystic fibrosis adults. In J. Hollmén, C. McGregor, P. Soda, \& B. Kane (Eds.), 2018 IEEE 31st International Symposium on Computer-Based Medical Systems (CBMS) (pp. 100-105). Los Alamitos, CA: IEEE Computer Society. https://doi.org/10.1109/ CBMS.2018.00025

van 't Riet, J., Meeuwes, A. C., van der Voorden, L., \& Jan-
Sz, J. (2018). Investigating the effects of a persuasive digital game on immersion, identification, and willingness to help. Basic and Applied Social Psychology, 40(4), 180-194. https://doi.org/10.1080/01973533. 2018.1459301

Venkatesh, V., Thong, J. Y., \& Xu, X. (2012). Consumer acceptance and use of information technology: Extending the unified theory of acceptance and use of technology. MIS Quarterly, 36(1), 157-178. https://doi.org/10.2307/41410412

Vyvey, T., Núñez Castellar, E. P., \& Van Looy, J. (2018). Loaded with fun? The impact of enjoyment and cognitive load on brand retention in digital games. Journal of Interactive Advertising, 18(1), 72-82. https:// doi.org/10.1080/15252019.2018.1446370

Whyte, E. M., Smyth, J. M., \& Scherf, K. S. (2015). Designing serious game interventions for individuals with autism. Journal of Autism and Developmental Disorders, 45(12), 3820-3831. https://doi.org/10.1007/ s10803-014-2333-1

Wouters, P., van der Spek, E. D., \& van Oostendorp, H. (2009). Current practices in serious game research. In T. Connolly, M. Stansfield, \& L. Boyle (Eds.), Games-based learning advancements for multi-sensory human computer interfaces (pp. 232-250). Hershey, PA: IGI Global. https://doi.org/ 10.4018/978-1-60566-360-9.ch014

\section{About the Author}

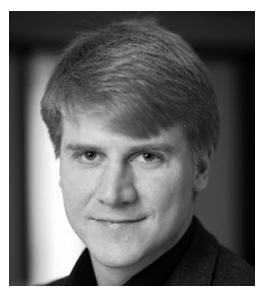

Ruud S. Jacobs researched the validation of persuasive games at the Erasmus University Rotterdam as part of the research project Persuasive Gaming. From Theory-Based Design to Validation and Back. Since defending his dissertation in 2017, he now works as an Assistant Professor of communication and technology at the University of Twente, among others lecturing in media psychology and investigating why people play serious games. 